\title{
ABSTRAK \\ HUBUNGAN PERILAKU MEROKOK DENGAN MEKANISME KOPING PADA REMAJA DI DESA PADANG KECAMATAN CAMPALAGIAN
}

\author{
Muhammad Syarif ${ }^{1}$, Lina Fitriani ${ }^{2}$, Mayawi Nurjannah Hamzah $^{3}$, Surya Rezki ${ }^{4}$
}

\section{Bab, 64 Halaman + xvii + 9 Lampiran}

Salah satu kebiasaan masyarakat saat ini yang dapat ditemui hampir di setiap akalangan masyarakat adalah perilaku merokok. Rokok tidaklah suatu hal yang baru dan asing lagi di masyarakat, baik itu laki-laki maupun perempuan, tua maupun muda. Orang merokok mudah ditemui, seperti di rumah, kantor, cafe, tempat-tempat umum, di dalam kendaraan, bahkan hingga di sekolah-sekolah (Redaksi Plus, 2010).Jumlah laki-laki yang merokok di Desa Padang pada tahun 2016 sebanyak 213 orang dan pada tahun 2017 meningkat menjadi 224..(Desa padang Kecamatan Campalagian Kabupaten Polewali Mandar tanggal 21 Januari 2018).

Dalam penelitian ini desain/rancangan yang digunakan adalah Dalam penelitian ini desain/rancangan yang digunakan adalah cross sectional yang merupakan rancangan penelitian yang pengukuran atau pengamatannya dilakukan secara stimultan pada satu saat (sekali waktu). (Aziz Alimul Hidayat, 2008. Jumlah Populasi 224 orang dengan sampel 24 orang, teknik pengambilan sampel accidental sampling.

Hasil Penelitian, uji statistik didapatkan bahwa hubungan prilaku merokok $(\mathrm{p}=0,000)$ dengan tingkat korelasi $(r=0,05)$ mempunyai hubungan prilaku merokok dengan mekanisme koping remaja $(\mathrm{p}=>0,05$ dengan tingkat korelasi $(\mathrm{r}=0,05)$ terdapat hubungan pada prilaku merokok remaja.

Berdasarkan hasil penelitian menunjukkan adanya hubungan perilaku merokok remaja dengan mekanisme koping remaja desa padang perlu diperhatikan untuk menurunkan angka perokok dan menurunkan tingkat stress yang terjadi di remaja akibat mekanisme koping yang belum baik.

Kata kunci : Perilaku Merokok, Mekanisme Koping

Daftar Pustaka : 27 (2007-2014)

\section{ABSTRACT \\ RELATIONSHIP BETWEEN SMOKING BEHAVIOR AND COOPERATION MECHANISM IN ADOLESCENTS IN PADANG VILLAGE CAMPALAGIAN DISTRICT}

Muhammad Syarif ${ }^{1}$, Lina Fitriani ${ }^{2}$, Mayawi Nurjannah Hamzah ${ }^{3}$, Surya Rezki ${ }^{4}$

5 Chapters, 64 Pages + xvii + 9 Attachments 
One of the habits of society today that can be found almost in every way of society is smoking behavior. Cigarettes are not new and unfamiliar in society, both men and women, young and old alike. Smoking people are easy to find, such as at home, office, cafe, public places, in vehicles, even in schools (Editor Plus, 2010). The number of men who smoke in Padang Village in 2016 is 213 people and in 2017 it increased to 224 .. (padang village, Campalagian, Polewali Mandar District, 21 January 2018).

In this study the design / design used was in this study the design / design used was cross sectional which was a research design whose measurement or observation was carried out simultaneously at one time (once). (Aziz Alimul Hidayat, 2008. Total population of 224 people with a sample of 24 people, accidental sampling technique.

Research Results, statistical tests found that the relationship of smoking behavior $(p=0,000)$ with the level of correlation $(r=0,05)$ had a relationship of smoking behavior with the coping mechanism of adolescents ( $\mathrm{p} \Rightarrow 0,05$ with the level of correlation $(\mathrm{r}=0,05)$ there is a relationship to adolescent smoking behavior.

Based on the results of the study showed that there is a relationship between adolescent smoking behavior and coping mechanisms of Padang village adolescents need to be considered to reduce the number of smokers and reduce the level of stress that occurs in adolescents due to poor coping mechanisms.

Keywords: Smoking Behavior, Koping Mechanism

Bibliography: 27 (2007-2014)

\section{PENDAHULUAN}

Latar Belakang

Salah satu kebiasaan
masyarakat saat ini yang dapat
ditemui hampir di setiap akalangan
masyarakat adalah perilaku merokok.
Rokok tidaklah suatu hal yang baru
dan asing lagi di masyarakat, baik itu
laki-laki maupun perempuan, tua
maupun muda. Orang merokok mudah
ditemui, seperti di rumah, kantor, cafe,
tempat-tempat umum, di dalam kendaraan, bahkan hingga di sekolahsekolah (Redaksi Plus, 2010).

Perilaku merokok merupakan perilaku yang merugikan, tidak hanya bagi individu yang merokok tetapi juga bagi orang-orang disekitar perokok yang ikut terhirup asap rokok. Kerugian yang ditimbulkan bias dari sisi kesehatan dan ekonomi. Dari sisi kesehatan, pengaruh bahan-bahan

kimia yang dikandung rokok seperti nikotin, karbon monoksida, dan tar akan memacu kerja dari susunan system saraf pusat dan sususan saraf simpatis sehingga mengakibatkan tekanan darah meningkat dan detak jantung bertambah cepat, menstimulasi kanker dan berbagai penyakit yang lain seperti pemyempitan pembuluh darah,tekanan darah tinggi, jantung, paru-paru, dan bronchitis kronis (Komalasari\&Helmi,2010)

Hasil riset Darson heodorus, menemukan bahwa stroke (Fawzani\&Triratnawati, 2008), Betapapun diungkapkan oleh berbagai kalangan peneliti tentang berbagai bahaya rokok bagi kesehatan, para perokok seakan-akan tidak peduli terhadap hasil berbagai penelitian itu.

Laporan World

HealthOrganization (WHO) tahun 
2008 menyatakan bahwa lebih dari lima juta orang meninggal karena penyakit yang disebabkan rokok. Ini berarti setiap satu menit tidak kurang sembilan orang meninggal akibat racun pada rokokatau dalam setiap tujuh detik akan terjadi satu kasus kematian akibat rokok.Pada tahun 2030 diperkirakan lebih dari $80 \%$ kematian akibat terjadi di negaranegara berkembang. Meningkatnya prevalensi merokok menyebabkan masalah rokok menjadi semakin serius. Jumlah perokok dunia mencapao 1,35 miliar orang (WHO,2008).

Di negara-negara berkembang, seperti di Indonesia jumlah perokok dari waktu ke waktu semakin meningkat. Pada tahun 1995 prevalensi perokok penduduk > 15 tahun adalah 26,9. Pada tahun 2001 meningkat menjadi 31,5(Lensa Indonesia,2011). Pada tahun 2007 mencapai 34,2 (Riskesdas,2007), kemudian pada tahun 2010 meningkat lagi menjadi 34,7

(Riskesdas,2010).Indonesia

merupakan salah satu negara dengan jumlah perokok terbesar didunia . Dari data WolrdHelathOrganization (WHO) pada tahun 2008, dapat disimpulkan bahwa Indonesia menempati urutan ketiga setelah China dan India pada sepuluh negara perokok terbesar didunia. Jumlah perokok Indoensia mencapai 65 juta penduduk.Sementara itu china mencapai 390 juta perokok dan India 144 juta perokok (Endrawanch, 2009).

Dari data WHO terhadap perokok di Indonesia memperlihatkan bahwa prevalensi perokok laki-laki jauh lebih tinggi dari apda perokok wanita. Demikian juga halnya provinsi Sulawesi Barat. Persentase perokok laki-laki yang merokok setiap hari adalah $61,4 \%$ dari jumlah penduduk laki-laki sedangkan perokok wanita yaitu 38,6 \% dari jumlah pendudk wanita (Riskesdes,2010). Jika diuraikan menurut umur, prevalensi perokok laki-laki paling tinggi menurut Riskesdas tahun 2010 adalah pada umur 15-19 tahun keatas).

Provinsi Sulawesi Barat menempati urutan kesembilan dari sepuluh provinsi dengan jumlah perokok terbesar di Indonesia (Riskesdas, 2010). Persentase penduduk yang merokok mencapai $38,4 \%$. Persentase ini dihitung berdasarkan jumlah penduduk di atas 15 tahun. Prilaku merokok di masyarakat tidak terjadi tanpa adanya hal-hal yang mendorong perokok untuk melakukan tindakan tersebut. Banyak faktor yang mendorong individu untuk merokok.Secara garis besar faktor-faktor yang mempengaruhi perilaku merokok adalah faktor lingkungan yang terdiri dari lingkungan keluarga dan lingkungan sebaya, serta kepuasan psikologis (Komalasari \& Helmi,2010).

Perokok di masyarakat Indonesia ternyata tidak hanya dikalangan dewasa saja, namun sudah merambat ke kalangan remaja. Data WHO tahun 2008 menyebutkan bahwa $63 \%$ pria adalah perokok dan $4,5 \%$ wanita adalah perokok. Sedangkan statistik perokok dari kalangan sensitivitas ketajaman penciuman dan pengecapan perokok berkurang dibanding dengan nonperokok. Sementara itu dari sisi 
ekonomi merokok pada dasarnya adalah membakar uang apalagi jika itu dilakukan oleh remaja yang belum mempunyai penghasilan.

Kepuasan psikologis member sumbangan yang lebih tinggi dari pada sumbangan sikap permisif orang tua dan lingkungan teman sebaya. Hal ini memberikan gambaran bahwa perilaku merokok bagi subjek dianggap memberikan kenikmatan dan menyenangkan. Merokok bagi remaja mempunyai kaitan yang erat dengan aspek psikologis terutama aspek positif yaitu sebesar $92,6 \%$ sedangkan efek negative hanya sebesar 7,5\% (pusing, ngantuk, danpahit).(KomalasaridanHelmi, 2010)

Perilaku merokok ini berkaitan erat dengan kondisi emosi, kondisi yang paling banyak perilaku merokok yaitu ketika subjek dalam tekanan atau stress yaitu sebesar 40,9\%. Individu yang merokok banyak beranggapan bahwa rokok dapat membantunya merasa lega dan santai saat stres, padahal yang dirasakan itu merupakan bentuk ketergantungan terhadap nikotin.

Remaja perempuan lebih peka terhadap lingkungannya. Nilai mereka di sekolah lebih baik, mereka juga lebih menonjol. Tuntutan dan motivasi mereka lebih tinggi. Akibatnya, remaja perempuan menderita beban psikis seperti cemas, tidak senang, sakit punggung dan sakit kepala. Sedangkan remaja laki-laki yang mengalami stress akan lebih sering merokok dan minum alkohol, sehingga dapat dikatakan bahwa stress merupakan salah satu keadaan yang menyebabkan remaja merokok (Nasotion 2010)

Stres merupakan bagian yang tidak terhindari dari kehidupan, stress mempengaruhi kehidupan setiap orang bahkan anak-anak danremaja. Kebanyakanstresdiusiaremajaberkaita ndengan masa pertumbuhan. MenurutNeedlman, (2004) stres yang terjadi pada remaja biasanya disebabkan dari beberapa factor diantaranya factor biologis, factor keluarga, factor sekolah, factor teman sebaya, dan factor lingkungan sosial.(Needlman,2014)

Perubahan perilaku pada remaja pada tingkat stress sedang bisanya seperti cemas berlebihan, gangguan tidur, mulai melakukan perilaku menyimpang, merokok, bolos sekolah. Pada tingkat stress berat biasanya anak merusak aspek fisiologis, perubahan perilaku remaja pada tingkat stress ini seperti, menarik diri atau menyendiri, menyakiti diri sendiri seperti merokok berlebihan, menggunakan obat-obatan bahkan sampai pada bunuh diri. (Sundeen, dalam Potter \& Perry, 2005).

Kemampuan seseorang remaja dalam mengatasi tergantung dari cara mereka mengatasi situasi biasanya disebut dengan mekanisme koping,mekanismekoping merupakan proses yang dilakukan oleh individu dalam meyelesaikan situasi yang penuh dengan tekanan dan juga terhadap situasi yang mengancam dirinya baik secara fisik maupun psikologik.(Sudeen, dalam

Potter\&Perry,2010).

Jumlah laki-laki yang merokok di Desa Padang pada tahun 2016 sebanyak 213 orang dan pada tahun 
2017 meningkat menjadi 224. Dari hasil studi pendahuluan 5 remaja perokok di desa Padang Kecamatan Campalagian Kabupaten Polewali Mandar, didapatkan 2 orang dapat mengendalikan stresnya atau koping adaptif sedangkan 3 tidak dapat mengendalikan stressnya atau kopingmaladaptif.(Hasil studi

\section{METODE PENELITIAN}

\section{Desain / Rancangan Penelitian}

Jenis penelitian yang dilakukan adalah cross sectional study yaitu suatu penelitian untuk mempelajari dinamika kolerasi antara faktor-faktor resiko dengan efek, dengan cara pendekatan, observasi atau pengumpulan data sekaligus pada suatu saat (Notoatmodjo, 2002), bertujuan untuk mencari jawaban tentang hubungan antara perilaku merokok dengan mekanisme koping remaja di desa Padang

\section{Populasi}

Adalah keseluruhan dari suatu variabel yang menyangkut masalah yang diteliti (Nursalam, 2000). Populasi adalah wilayah generalisasi yang terdiri atas pendahuluan di Desa padang Kecamatan Campalagian Kabupaten Polewali Mandar tanggal 21 Januari 2018).

Oleh karena itu penulis tertarik untuk mengangkat ju'ı1 "Hubungan Perilaku Merokol Terhadap Mekanisme Koping Remaja di Desa Padang Kecamatan Campalagian"

objek/subjek yang mempunyai kuantitas dan karakteristik tertentu yang ditetapkan oleh peneliti untuk dipelajari dan kemudian ditarik kesimpulannya, (Sugiyono, 2004). Populasi dapat bersifat terbatas dan tidak terbatas. Dikatakan terbatas apabila individu atau objek dalam populasi tersebut terbatas dalam arti dapat dihitung. Sedangkan bersifat tidak terbatas dalam arti tidak dapat ditentukan jumlah individu atau objek dalam populasi tersebut. Populasi dalam penelitian ini adalah 224 remaja di Desa Padang

\section{Sampel}

Sampel dalam penelitian ini adalah menggunakan teknik Accidental sampling yaitu teknik mengambil sampel yang ditemui sesuai kriteria penelitian(Azwar, 1999). Dalam penelitian ini sampel yang di gunakan adalah sebanyak 24 remaja yang merokok di Desa Padang.

\section{Hasil Penelitian}

Penelitian ini dilaksanakan di desa padang kecamatan campalagian kabupaten polewali mandar, proses pengumpulan data dilakukan dengan berpedoman pada kuesioner penelitian yang dilaksanakan pada tanggal 15 juni sampai dengan 5 juli 2018.

Berdasarkan pengolahan data yang dilakukan, diperoleh hasil yang disajikan secarasi stematis sebagai berikut :

\section{Analisa Univariat}

Karakteristik responden berdasarkan jenis kelamin 
Distribusi seluruh responden yang perokok di desa padang kecamatan campalagian kabupaten polewali mandar bulanJunitahun 2018 berdasarkan jenis kelamin adalah :

Tabel 4.1

Distribusi Responden Berdasarkan Jenis Kelamin Pada Remaja Perokok Di Desa Padang Kecamatan Campalagian

Kab.Polewali Mandar

\begin{tabular}{|c|c|c|c|}
\hline No. & Jenis Kelamin & Jumlah & $\%$ \\
\hline 1 & Laki-laki & 24 & $100 \%$ \\
\hline 2 & Perempuan & 0 & $0 \%$ \\
\hline \multicolumn{2}{|c|}{ Jumlah } & 24 & $100 \%$ \\
\hline
\end{tabular}

Sumber : data Primer

Gambar 4.1 pada tabel diatas menunjukkan bahwa responden remaja perokok pada desa padang kecanatan campalagian kabupaten polewali mandar pada saat pengumpulan data dengan distribusi tertinggi adalah jenis kelamin laki-laki sebanyak $24(100 \%)$ dan terendah adalah berjenis kelamin perempuan sebanyak responden $(0 \%)$.

\section{Karakteristik responden berdasarkan umur}

Distibusi responden berdasarkan umurnya ditampilkan pada tabel berikutini :

Tabel 4.2

DistribusirespondenberdasarkanumurPada Remaja Perokok Di

Desa Padang Kecamatan Campalagian

Kabupaten Polewali Mandar

\begin{tabular}{|c|c|c|c|}
\hline No. & Umur & Jumlah & $\%$ \\
\hline 1 & $11-15$ tahun & 13 & $54 \%$ \\
\hline 2 & $16-21$ tahun & 11 & $46 \%$ \\
\hline \multicolumn{2}{|c|}{ Jumlah } & 24 & $100 \%$ \\
\hline
\end{tabular}

Sumber : data Primer

Berdasarkan tabel $\quad 4.2$ Menunjukkan bahwa distibusi responden berdasarkan umur remaja didapatkan pada umur 11-15 tahun berjumlah 13 (54\%) dan pada umur 15-21 tahun didapatkan sebanyak 11 (46\%). Pada penelitian ini apabila dilihat dari factor usia kabanyakan berusia11-15 tahun, ituberarti pada usia tersebut kebanyakan mereka memiliki mekanisme koping yang maladaptif

Karakteristik responden berdasarkan kategori perokok

Tabel 4.3

DistribusiRespondenBerdasarkanKategoriPerokok Pada Remaja Di Desa Padang Kecamatan CampalagianKabupaten Polewali Mandar 


\begin{tabular}{|c|c|c|c|}
\hline No. & Kategori Perokok & Jumlah & $\%$ \\
\hline 1 & Ringan & 7 & $33 \%$ \\
\hline 2 & Berat & 17 & $67 \%$ \\
\hline & Jumlah & 24 & $100 \%$ \\
\hline
\end{tabular}

Sumber : data Primer

Seperti tampak pada tabel 4.6 berdasarkan kategori merokok pada remaja di desa padang kecamatan campalagian kabupaten polewali mandar kategori perokok ringan terbanyak dengan jumlah 8 orang responden (33\%), dan kategori perokok berat hanya 16 orang (67\%). Ini menunjukkan ketegori perokok berat terbanyak diantara responden yang merokok di desa padang kecamatan polewali kabupaten polewali mandar

Karakteristik responden tentang kemampuan mekanisme koping remaja

Tabel 4.4

DistribusiRespondenBerdasarkanMrekanismeKoping Remaja Di Desa Padang Kecamatan Campalagian Kabupaten Polewali Mandar

\begin{tabular}{|c|c|c|c|}
\hline No. & Mekanisme Koping & Jumlah & $\%$ \\
\hline 1 & Maladaptif & 16 & $67 \%$ \\
\hline 2 & Adaptif & 8 & $33 \%$ \\
\hline & Jumlah & 24 & $100 \%$ \\
\hline
\end{tabular}

Sumber : data Primer

Pada tabel 4.4

menunjukkan bahwa responden dengan distribusi terbanyak mekanisme koping maladaptif sebanyak 16 orang responden (67\%), sedangkan yang mekanisme koping adaptif relatif rendahsebanyak8 orang responden $(33 \%)$.

\section{Analisa Bivariat}

Analisa bivariat dalam penelitian ini adalah untuk mengetahui hubungan perilaku merokok dengan mekanisme koping pada remaja di desa padang kecamatan campalagian kabupaten polewali mandar yaitusebagaiberikut : 
Tabel 4.5 Hubungan Prilaku Merokok dengan Mekanisme Koping

\section{PerilakuMerokokRemaja * MekanismeKopingRemaja}

Crosstabulation

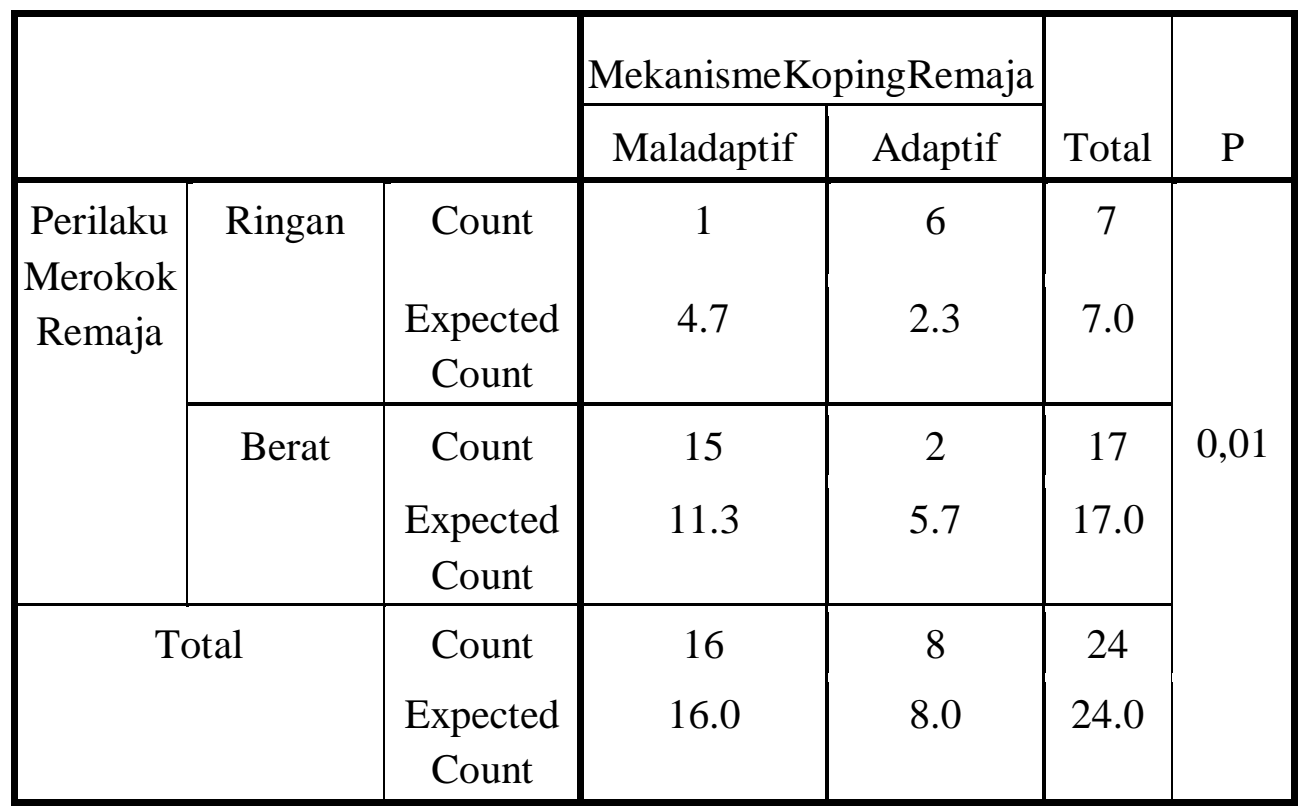

Sumber : data sekunder

Distribusi

responden

berdasarkan tabel 4.5 hubungan

perilaku merokok dengan

mekanisme koping remaja di desa padang kecamatan campalagian, responden yang mempunyai perilaku merokok dikategorikan menjadi perokok ringan sebanyak 6 orang (25\%) yang mempunyai mekanisme koping maladaptif 1 orang $(4,1 \%)$, pada perilaku merokok berat dengan mekanisme koping adaptif sebanyak $2(8,3 \%)$ sedangkan yang maladaptif 15 orang $(62,8)$.
Berdasarkan chi-square dengan nilai kemaknaan $\alpha: 0,05$ dimana hasil penelitian diperoleh $\mathrm{p}$ : 0,001 yang menunjukkan $\mathrm{P}<\alpha$ atau $0,0001<0,05$ maka $\mathrm{H} 1$ diterima dan Ho ditolak. Hal ini menunjukkan ada hubungan antara prilaku merokok dengan mekanisme koping remaja di desa padang kecamatan campalagian..Sehingga dapat disimpulkan bahwa dari perilaku merokok berhubungan dengan mekanisme koping remaja di desa padang kecamatan campalagian. 


\section{Pembahasan}

Perilaku Merokok

Berdasarkan hasil pengelolahan data yang dilakukan, dalam bentuk pembahasan ini diarahkan sesuai dengan tujuan penelitian yaitu untuk mengetahui hubungan perilaku merokok dengan mekanisme koping didesa padang kecmatancampalagian. Dari data tabel 4.3 didapatkan perokok berat sebanyak 17 orang $(67 \%)$, dan perokok ringan 7 orang (33\%). Disimpulkan kebanyakan remaja di desa padang kebanyakan prilaku merokoknya berat

$\begin{array}{ccc}\text { Merokok } & \text { merupakan } & \text { suatu } \\ \text { aktifitasmemnbakar } & \text { tembakau } & \text { yang }\end{array}$
kemudian dihisap asapnya baik menggunakan rokok maupun menggunakan pipa yang dilakukan secara berulang-ulang. Aktivitas merokok itu sendiri sudah tidak lagi terlihat dan terdengar asing lagi bagi kita. Sekarang banyak sekali bisa kita temui orang orang yang melakukan aktifitas merokok yang disebut sebagai perokok.(Rogayah,2012).

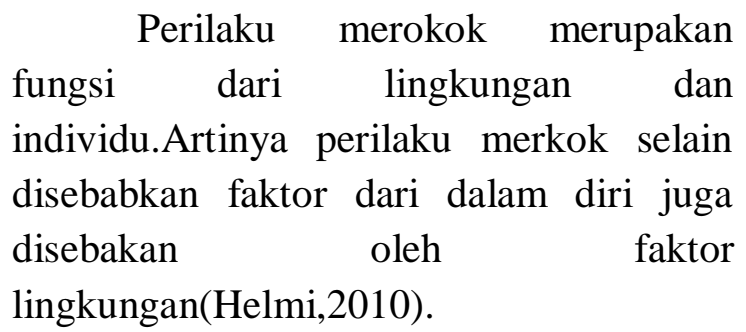

Salah satu faktor internal penyebab perokok adalah faktor kepribadian, induvidu mencoba untuk merokok alasan ingin tahu atau ingin melepaskan dari rasa sakit atau kebosanan.(Smet,2007)

Sedangkan salah faktor eksternal adalah faktor lingkungan sosial dapat juga berpengaruh terhadap sikap,kepercayaan, dan perhatian individu pada perokok.Seseorangberprilaku merokok dengan memperhatikan lingkungan sosialnya.(Smet,2007).

Bahaya merokok menurut (Depkes RI dalamPoltekkesDepkes, 2010) adalah: a. Bagi perokok aktif, yaitu sesorang yang merokok secara langsung atau menghisap rokok (Thayyarah, 2013) 1) Meningkatkan risiko dua kali lebih besar untuk mengalami serangan jantung. Merokok dapat meningkatkan tekanan darah dan mempercepat denyut jantung sehingga pemasokan zat asam kurang dan keadaan ini memberatkan tugas otot jantung. Merokok dapat mempertebal dinding pembuluh darah yang berakibat jantung kesulitan dalam memompa darah (Nururrahmah,2014). 2) Meningkatkan risiko dua kali lebih besar untuk mengalami stroke3) Meningkatkan risiko mengalami serangan jantung dua kali lebih besar pada mereka yang mengalami tekanan darah tinggi atau kadar kolesterol tinggi 4) Meningkatkan risiko sepuluh kali lebih besar untuk mengalami serangan jantung bagi wanita pengguna pil KB 5) Meningkatkan risiko lima kali lebih besar menderita kerusakan jaringan anggota tubuh yang rentan. Zat dalam rokok yang bersifat karsinogenik adalah tar, dapat meyebabkankan kerparu paru karena sebagian besar zat ini tersimpan didalamparu-paru. Selain itu, tar ini dapat menyebakan kanker jika merangsang tubuh dalam waktu yang lama, biasanya didaerah mulut dan tenggorokan (Nururrahmah,2014).

\section{Mekanisme Koping}

Dari hasil tabel 4.4 didapatkan mekanisme koping remaja dari 24 orang 
perokok yaitu mempunyai kemampuan mekanisme adaptif 16 orang (67\%) sedangkan yang mempunyai kemampuan mekanisme maladaptif 8 orang (33\%). Dari data diatas mekanisme koping remaja didesa padang kebanyakan maladaptif.

Mekanisme koping merupakan suatu proses mental untuk mengatasi tuntunan yang dianggap sebagai tantangan terhadap sifat pada diri seseorang. Dalam hal ini, untuk dapat melakukan koping diperlukan sifat internal dan sifat eksternal. (Widiastuti,2013).

\section{Menurut Nursalam mekanisme yang digunakan individu untuk menghadapi perubahan yang diterima. Apabila mekanisme koping ini berhasil, maka individu tersebut akan dapat beradaptasi terhadap perubahan yang terjadi. Mekanisme koping dapat dipelajari, sejak awal timbulnya stressortersebut.Kemampuankoping individu tergantung dari temperamen,presepsi, dan kognisi serta latar belakang budaya atau norma tempatnya dibesarkan,(Nursalam,2013)}

\section{Hubungan Prilaku Merokok dan Mekanisme Koping}

Berdasarkan chi-square dengan nilai kemaknaan $\alpha: 0,05$ dimanahasil penelitian diperoleh $\mathrm{p}: 0,001$ yang

\section{Kesimpilan Dan Saran}

\section{Kesimpulan}

Berdasarkan penelitian dan hasil pembahasan yang dilakukan, maka dapat disimpulkan sebagai berikut :

Diperolehhasil pada kategoriperokokringanterbanyakdenganju menunjukkan $\mathrm{P}<\alpha$ atau $0,0000<0,05$ maka H1 diterima dan Ho ditolak. Hal inimenunjukkan ada hubungan antara prilaku merokok dengan mekanisme koping remaja di desa padang kecamatan campalagian.

Sesuai teori yang mengatakan bahwa individu dapat beradaptasi dan tidak menimbulkan suatu gangguan kesehatan, tetapi bila mekanisme koping gagal untuk beradaptasi dapat menimbulkan stress (Hisbuan,2012)

Stress merupakan bagian yang tidak terhindari dari kehidupan, stress mempengaruhi kehidupan setiap orang bahkan anak-anak dan remaja. Kebanyakan stressdiusia remaja berkaitan dengan masa pertumbuhan. Menurut Needlman, stres yang terjadi pada remaja biasanya disebabkan dari beberapa faktor diantara faktor teman sebaya, dan faktor lingkungan sosial (Needlman,2014).

Kemampuan seseorang remaja dalam mengatasi masalah tergantung dari cara mereka mengatasi situasi biasanya disebut dengan mekanisme koping, mekanisme koping merupakan proses yang dilakukan oleh individu dalam menyelesaikan situasi yang penuh dengan tekanan dan juga terhadap siatuasi yang mengancam dirinya baik secara fisik maupun psikologik(Sundeen,2010

mlah8 orang responden (33\%), dan kategoriperokokberathanya 17 orang $(67 \%)$.

Diperolehhasil pada tabel 4.4 menunjukkan bahwa responden dengan distribusi terbanyak mekanisme koping maladaptif sebanyak16 orang responden (67\%), sedangkan yang mekanisme koping 
adaptif relatif rendahsebanyak8 orang responden $(33 \%)$..

Diperoleh distribusi responden berdasarkan tabel 4.5hubungan perilaku merokok dengan mekanisme koping remaja di desa padang kecamatan campalagian, responden yang mempunyaiperilakumerokokdikategorikan menjadiperokokringan sebanyak 6 orang (25\%) yang mempunyai mekanisme kopingmaladaptif 1 orang $(4,1 \%)$, pada perilaku merokok berat dengan mekanisme koping adaptif sebanyak 2 (8,3\%) sedangkan yang maladaptif 15 orang $(62,8)$.

Berdasarkan chi-square dengan nilai kemaknaan $\alpha$ : 0,05 dimana hasil penelitian diperoleh $\mathrm{p}: 0,000$ yang menunjukkan $\mathrm{P}<\alpha$ atau $0,0000<0,05$ maka $\mathrm{H} 1$ diterima dan Ho ditolak. Hal inimenunjukkan adahubungan antara prilaku merokok dengan mekanisme koping remaja di desa padang kecamatan campalagian..Sehingga dapat disimpulkan bahwadari perilaku merokok berhubungan dengan mekanisme koping remaja di desa padang kecamatan campalagian.

\section{DAFTAR PUSTAKA}

A.AzisAlimulHidayat(2012).

PengantarKebutuhanDasarManusi

a, AplikasaiKonsepdan Proses

Keperawatan I.Jakarta

:SalembaMedika

A.AzisAlimulHdayat (2012).

RisetKeperawatandanTeknikPenuli sanIlmiah. Edisi 2,SalembaMedika : Jakarta

\section{Saran-Saran}

Berdasarkan kesimpulan diatas, maka disarankan :

\section{Bagi Desa Padang}

Diharapkan agar meningkatkan penyuluhan tentang rokok di desa padang untuk meningkatkan kemampuan mekanisme koping remaja di desa tersebut.

\section{Bagi Institusi Pendidikan}

Diharapkan agar hasil penelitian ini merupakan referensi secara ilmiah dalam penelitian dan keilmuan selanjutnya.

\section{BagiProfesiKeperawatan}

Diharapkan agar lebih mendalami hal-hal menyangkut kesehatan agar meningkatkan penyuluhan bahaya merokokuntuk meningkatkan mekanisme koping remaja di desa padang dan menghindari prilaku perokoknya.

Aaro,L.E.(2010) Aldolscent lifestyle,

Dalam A/ Baum ,

S.NewmanJ.Welnman.R, West ad

C. Mcmanus (Eds). Cambridge

Uniersity Press Cambridge.

Endrawanch, 2009,10 Negara

dengaNJumlahPerokokTerbesar di

DuniaDiaksespadatanggal 20

Januari 2018,

darihttp://www.lintasberita.com/Du nia/BeritaDunia/10_Negara_denga 
n_Jumlah_Perokok_Terbesar_di_D

unia

Helmi,A.F. (2016). Faktor-

faktorPenyebabPerilakuMerokokpa daRemaja.JurnalPsikologiUniversit asGadjahMada

Heryani, R, 2014 Kumpulan Undang-

UndangdanPeraturanPemerintahR

epublik Indonesia

KhususKesehatan.Jakarta :CV.

Trans Info Media

Jaya Mhammad (2009)

PembunuhBerbahayaItuRokok,

JogyakartaIndonesa.

Komalasari, D \&Helmi A F. (2010).

Faktor-

faktorPenyebabPerilakuMerokokP

adaRemajaJurnalPsikologi. (1) (di

unduhpadatanggal 14 Januari 2018)

Mathew B. \& A. Michael

Huberman.2008.Analisa Data

Kulitatif.Jakarta: UI-Press.

Mustikasari. (2011). MekanismeKoping.

Penprofil.

Jakarta:PenerbitRinekaCipta

Nasution, (2009),

InfeksiSaluranPernafasanAkutpada

Balita d Daerah Urban

Jakarta.SariPediatri.Volume. 11.

No.4 Desember 2009/

Nevid, J.S. Rathus, S.A. dan Beverly

G.2010 Psikologi Abnormal.

Jakarta :Erlangga.
Notoatmojo, S. 2010.

MetodologiPenelitianKesehatan.

Jakarta :RinekaCipta.

Nursalam, (2013). Konsep Dan

PenerapanMetodologiPenelitianIl

muKeperawatan. Edisi.2. Jakarta

:SalembaMedika).

Octarina,M. da Rachmawati, M.(2008).

HubunganAntaraKonformitasdeng

anPerilakuMerokok Yogyakarta:

Program

StudiPsikologiFakultasPsikologida

nIlmuSosialBudayaUniverstas

Islam Indonesia

Papila,D E., olds,S.W.,\&Feldman,Ruth

D.(2007).Human

development(8thed).Boston:McGra

w-Hill

Potter \& Perry. 2010. Buku Ajar

Fundamental Keperawatan .Jakarta

: EGC

Redaksi plus (2010). Stop Rokok, Mudah,

Murah, Cepat. Depok

:PenerbitSwadaya

Rice.,F.P (2009). The aldoescent

development, relationship\& culture

$\left(6^{\text {th }} e d\right)$.Boston: Ally\& Bacon

Rogyah R. 2012.

AsapRokokSebagaiBahanPencema

$r$. Jakarta :PT.

GramediaWidiansarana Indonesia

Smet,B. PsikologiKesehatan. 2007. Jakarta

: PT GramediaWidiaansarana

Indonesia 
WHO, Global Youth Tobacco Survey :

Indonesiareport 2014. Regional

Office for South-East-Asia. New

Delhi:WHO,2014

Widyastuti P. 2008.Manajemen

Stress.,Penerjemah;Yulianti D,

editor. Jakarta:EGC.

Tercemahandari Stress

Management
Wills (2011). Midlle Rage Theories:

Application to Nursing Research

Philadelphia:Lippincott Wilkins

Yuliayanti C, 2013

PengaruhDukunganKeluarga,

dukunganpelatih,

danstrategikopingterhadapprestasi

atletmuda di SMA NegeriRagunan

Jakarta Bogor: Program

SarjanaInstitutPertanian Bogor. 